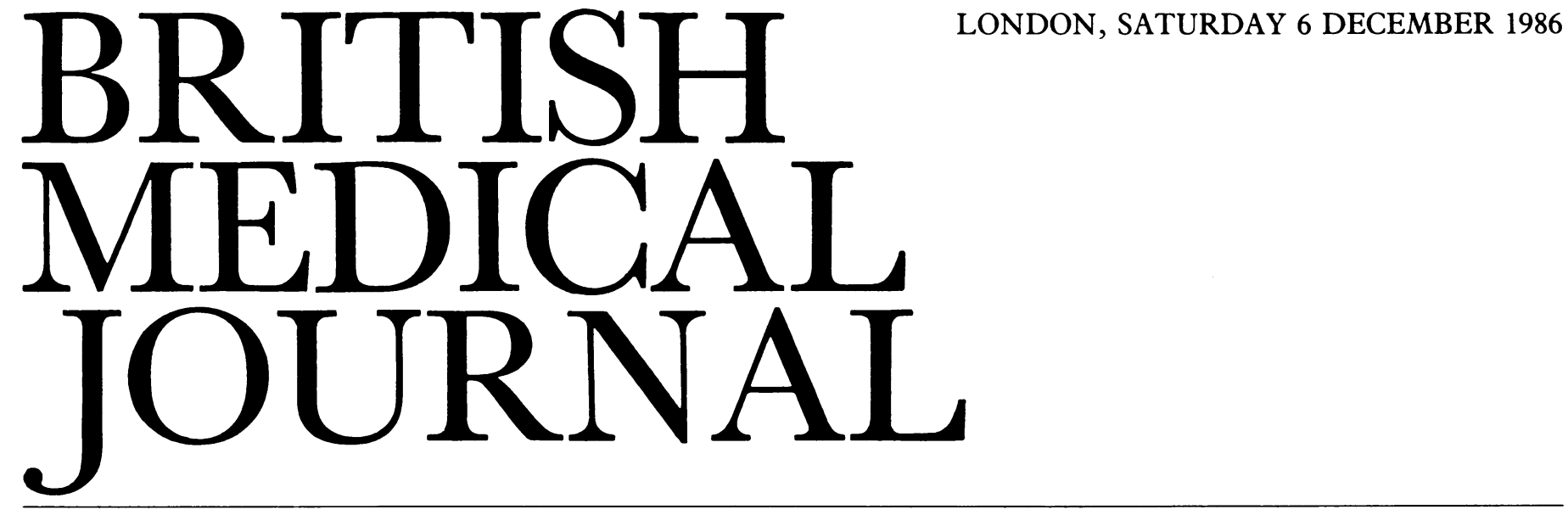

\title{
The clinical features of HIV infection in Africa
}

The central part of Africa is in the midst of an epidemic of acquired immune deficiency syndrome (AIDS). ${ }^{1}$ Recent studies from cities in Zaire, ${ }^{2}$ Zambia, ${ }^{3}$ Kenya,${ }^{4}$ and Rwanda ${ }^{5}$ show that human immunodeficiency virus (HIV) is spread mainly through heterosexual transmission and that the highest prevalences of antibodies to HIV are found in the most sexually active groups. As many as $5-10 \%$ of the young adults in some urban areas have antibodies against HIV, ${ }^{23}$ and the infection is spreading to rural populations ${ }^{6}$ and children.

A key question for predicting the future effects of AIDS in Africa is what will happen to those who have antibodies to HIV. American and European experience is that HIV infection causes a slow decline of cell mediated immune function that usually takes several years to become clinically important. ${ }^{8}$ AIDS has occurred in $15-30 \%$ of Americans from the groups most at risk within three years of them being found to have antibodies to HIV, and the incidence continues to rise steadily. ${ }^{9}$ How long these people had had antibodies is not known, and since the length of time people have had antibodies is the major factor known to determine risk of developing AIDS, ${ }^{10}$ only time will tell what proportion of infected people will progress to AIDS.

Are the clinical implications of infection with HIV in Africa the same as in America and Europe? Sadly, the answer appears to be yes. Africans with antibodies to HIV have had virtually all of the manifestations of AIDS seen in Americans and Europeans, including acute HIV seroconversion syndrome with encephalitis, asymptomatic immunodepression (as manifest by low numbers of $\mathrm{T}$ helper cells and inverted $\mathrm{T}$ lymphocyte helper to suppressor ratios), persistent generalised lymphadenopathy, lesser AIDS conditions (such as oral candidiasis and infection with herpes zoster), aggressive Kaposi's sarcoma, and a myriad of opportunistic infections.' Only one study has measured the risk of AIDS among healthy Africans with antibodies to HIV, and it found a $1 \%$ risk of AIDS after one year-but this probably underestimates long term risk. ${ }^{11}$

The differences between the environments in Africa and elsewhere might make for differences in the types and frequency of potential pathogens affecting immunodeficient patients. But so far African cases of AIDS have generally resembled those seen in the United States, Europe, and Haiti. ${ }^{1}$ Pneumonia caused by Pneumocystis carinii seems less common among African than among American or European patients with AIDS, even among African patients with AIDS studied in Europe. In contrast, toxoplasmosis is more common among Africans. Malaria has not been reported to be more severe or common among patients with AIDS. Candida infections are common in all areas, and cryptococcosis is common in patients with AIDS in some parts of Africa, particularly Zaire. Tuberculosis caused by Mycobacterium hominus occurs in patients with AIDS in all areas but is more common in Africa because tuberculosis is more common. In patients with immunodeficiency induced by HIV it may be more severe, but most patients with tuberculosis in Africa do not have antibodies to HIV. Helminthic infections have not emerged as major problems.

Viral infections among African patients with AIDS are poorly studied because of the lack of facilities but are probably similar to those elsewhere-with cytomegalovirus infection being most serious. An enteropathic version of AIDS - known locally in Uganda as "slim disease" because of cachexia associated with diarrhoea ${ }^{6}$ - is common but not yet well studied. Some cases may be found to have previously recognised diseases, but the pathogenesis of the wasting syndrome often defies diagnosis even among closely studied American and European patients.

Kaposi's sarcoma of the aggressive type seen among American and European patients with AIDS has been associated with HIV infection and immunodeficiency in Africa. ${ }^{12}$ Generally these constitute less than $10 \%$ of African cases, although there may be regional differences. Indolent Kaposi's sarcoma unrelated to infection with HIV or immunosuppression is endemic in a belt in east central Africa, ${ }^{13}$ and aggressive Kaposi's sarcoma associated with HIV has been most often reported in areas where this belt overlaps with the areas in which HIV is epidemic-such as Zambia ${ }^{14}$ and Uganda. ${ }^{12}$ Perhaps immunodeficiency induced by HIV unmasks another cofactor for Kaposi's sarcoma such as an infectious agent endemic in this belt. Data from the United States show that AIDS is associated with B cell nonHodgkin's lymphomas, including Burkitt-like lymphomas. ${ }^{15}$ Yet no association has yet been seen in Africa despite the relatively high prevalence of Burkitt's lymphoma in some areas; this may be because African Burkitt's lymphoma is a disease of mid-childhood, a time when HIV infection is uncommon.

Doctors in Africa often have only clinical acumen to guide them in diagnosing AIDS, but simple, rapid tests for 
antibodies to HIV should soon become available. Negative results should ease concerns about AIDS, but systematic research will be needed to distinguish illnesses in people incidentally infected with HIV from those in people with HIV induced immunosuppression. The distinction is crucial since it is the progressive immunodeficiency, not simply having antibodies to HIV, that is associated with a poor short term prognosis.

What is critically important about AIDS in Africa, however, is the enormity of the problem. Already many central and east Africans are infected with HIV, and if these people develop AIDS at the same rate as elsewhere a huge increase in the number of cases of AIDS will occur in the next few years. Even if effective treatments are developed for HIV infection and immunodeficiency, applying these in Africa to many thousands of cases will be difficult if not impossible. Only prevention holds any promise of limiting the tragedy, and education about sexual transmission and programmes to eliminate parenteral exposure from infected blood or contaminated needles are essential - but ultimately a vaccine will be needed.

Head, International AIDS Epidemiology,

ROBERT J BIGGAR

Environmental Epidemiology Branch,

National Cancer Institute,

Bethesda,

Maryland 20205, USA

1 Biggar RJ. The AIDS problem in Africa. Lancet 1986;: $79-83$.

2 Mann JM, Francis $\mathrm{H}$, Quinn T, et al. Surveillance for acquired immunodeficiency syndrome in a Central African city: Kinshasa, Zaire. FAMA 1986;255:3255-9.

3 Melbye M, Nielesani EK, Bayley A, et al. Evidence of heterosexual transmission and HIV-related conditions among healthy and hospitalized Africans: an epidemiologic survey in Lusaka, Zambia, 1985. Lancet (in press).

4 Kreiss JK, Koech D, Plummer FA, et al. AIDS virus infection in Nairobi prostitutes: spread of the epidemic in East Africa. N Engl I Med 1986;314:414-8.

5 Van de Perre P, Clumeck N, Carael M, et al. Female prostitutes: a risk group for infection with human T-cell lymphotropic virus type III. Lancet 1985; ii:524-6.

6 Serwadda D, Mugerwa RD, Sewankambo NK, et al. Slim disease: a new disease in Uganda and its association with HTLV-III infection. Lancet 1985; ;i:849-52.

7 Mann JM, Francis H, Davachi F, et al. Risk factors for human immunodeficiency virus seropositivity among children 1-24 months old in Kinshasa, Zaire. Lancet 1986;ii:654-7.

8 Melbye M, Biggar RJ, Ebbesen P, et al. Long-term seropositivity for human T-lymphotropic virus type III in homosexual men without the acquired immunodeficiency syndrome: virus type
development of immunologic and clinical abnormalities. A longitudinal study. Ann Intern Med development of im

9 Goedert JJ, Biggar RJ, Weiss SH, et al. Three-year incidence of AIDS in five cohorts of HTLV III-infected risk group members. Science 1986;231:992-5.

10 Goedert JJ, Biggar RJ, Melbye M, et al. Effect of T4 count and cofactors on AIDS incidence in homosexual men infected with immunodeficiency virus. JAMA (in press).

11 Mann JM, Bila K, Colebunders RL, et al. Natural history of human immunodeficiency virus infection in Zaire. Lancet 1986;ii:707-9.

12 Bayley AC, Downing RG, Cheingsong-Popov R, Tedder RS, Dalgleish AG, Weiss RA. HTLV-III distinguishes atypical and endemic Kaposi's sarcoma in Africa. Lancet 1985; 359-61.

13 Kestens L, Melbye M, Biggar RJ, et al. Endemic African Kaposi's sarcoma is not associated with immunodeficiency. Int $\mathcal{f}$ Cancer 1985;36:49-55.

14 Bayley AC. Aggressive Kaposi's sarcoma in Zambia, 1983. Lancet 1984;i:1318-20.

15 Biggar RJ, Horm J, Lubin JH, Goedert JJ, Greene MH, Fraumeni JF Jr. Cancer trends in a population at risk of AIDS. $\mathcal{F}$ Natl Cancer Inst 1985;74:793-7.

\section{A limited role for manipulation}

Whatever treatment is offered $80-90 \%$ of patients with backache will be free of symptoms within about two weeks. Many patients, however, suffer frequent attacks, and some have persistent pain with occasional exacerbations. Against this background it is difficult to assess the value of any treatment-including manipulation. Two previous leading articles in the $B M \mathcal{F}$ have considered the uncertainties over manipulation and called for controlled trials. ${ }^{12}$ In this issue two manipulators-one medically qualified, the other an osteopath-give their views on the value of manipulation (pp 1481 and 1482).
Manipulation might be viewed as an art rather than a science as each therapist has an individual approach and modulates treatment techniques in a personal way for each patient. ${ }^{3}$ This might seem to make scientific assessment of its value hopeless, but scientists believe that such an assessment should be possible given sufficient commitment and resources.

Manipulation includes manual methods of diagnosis as well as of treatment, and the system of diagnosis is not that of conventional medicine. Manipulators observe, feel, and describe spinal lesions such as subluxation and vertebral fixation and blockage. They find malposition of vertebrae with abnormal vertebral motion and joint play, soft tissue abnormalities, and muscle contractures. A pathological basis for these lesions has not been shown, but that does not mean that any abnormalities are not there-because pathological examination is obviously almost impossible in such circumstances.

The treatment that the manipulator offers a patient depends on his physical findings and is modulated according to the patient's progress. In "non-specific long lever manipulation" rotational forces are applied to the spine through the shoulder, pelvic girdle, or even limbs. In "specific short lever manipulation," in contrast, small amplitude high velocity adjustments are applied manually to individual segments of the spine through the spinous or transverse processes. These manipulative techniques may be supplemented by a wide range of treatments such as mobilisation, muscle traction, and soft tissue massage. Assessing whether manipulation works is complicated not only by the wide range of treatments, but also by the fact that surgeons, physicians, physiotherapists, osteopaths, chiropractors, and others all manipulate in different ways. Furthermore, some are much more skilful than others.

How manipulation might work is uncertain. It may mobilise stiff joints and free adhesions, but it may also produce neurophysiological stimulation with afferent impulses that suppress pain. In addition, the "hands-on" attention of the manipulator must produce powerful psychological effects. ${ }^{4}$

A control group is thus essential for any adequate trial of manipulation, and such trials are rare. ${ }^{5-13}$ Some suggest that manipulation may hasten the recovery of those who are going to recover anyway. In the first adequately controlled trial those who were manipulated had significantly better relief 15 minutes after manipulation, but after three days this benefit was lost. ${ }^{5}$ Another study in general practice also showed that patients were significantly better than controls immediately after treatment, but again the advantage had been lost after about two months. ${ }^{6}$ The study referred to by Dr Grayson ${ }^{7}$ suggested that recovery was more rapid over the first two weeks following manipulation but thereafter there was no difference between treated patients and controls. A comparison of manipulation and soft tissue massage showed significantly better immediate relief in those manipulated, but again three weeks later - when both groups had improved substantially - the difference had disappeared. ${ }^{8}$

Other studies, however, have failed to show significant differences between patients manipulated and controls, ${ }^{9-12}$ although in two studies there were minor indications that the manipulated patients might have improved more quickly. ${ }^{910}$ Any benefit may relate to the total amount of physical therapy rather than to any specific form of treatment. ${ }^{10}$ Whatever benefits there might be from manipulation seem to be confined to those with acute pain of recent onset. There is no evidence that manipulation helps those with severe or 